\title{
Cytokine Profile in JE and non JE Encephalitis
}

\author{
Mahima Mittal ${ }^{1}$, Mohammed Junaid Ansari ${ }^{2}$, Shahla Abrar ${ }^{3}$, Ashok K. Pandey ${ }^{4}$ \\ ${ }^{1,2,3}$ Department of Pediatrics, B.R.D. Medical College, Gorakhpur, UP, India \\ ${ }^{4}$ National Institute of Virology, Gorakhpur Unit, Gorakhpur, UP, India
}

\begin{abstract}
Background \& Objectives: Encephalitis is parenchymal brain inflammation due to infectious or immune-mediated processes. Acute Encephalitis Syndrome due to unidentified causes has been an issue of concern in eastern Uttar Pradesh. This study was undertaken to study the cytokine response in JE and non JE AES. Methodology: This prospective study was performed in patients with acute encephalitis syndrome (AES) aged 1 to 15 years who had been admitted to a tertiary care teaching hospital. Patients who tested positive for typhoid, malaria, measles, mumps, herpes(HSV), Dengue were excluded. Serum and CSF samples of JE positive and non JE cases were further analysed for cytokine levels - Tumor necrosis factor - $\alpha$, Interferon- $\gamma$, Interleukin-10 and chemokines interferon activated protein-10 and RANTES. Results: 12 were positive for JE IgM and 58 cases were from the Non JE category in which no aetiology was detected. Cytokines were tested in 45 patients, 12 were of JE and rest 33 of non JE. CSF level of IFN- $\gamma$, IL-10 and IP-10 were significantly higher in Non JE patients than in JE patients. IP-10 cut off levels in CSF of more than 1223.24 were helpful in differentiating non JE from JE with a sensitivity of $72.73 \%$ and specificity of $66.63 \%$. Conclusion: This study highlights the differences in immunological response of the JE and non JE cases. Interferon gamma inducible protein-10 (IP-10), a chemokine was siginificantly increased in the non JE group and turned out to be a fairly sensitive test in differentiating JE from non JE.
\end{abstract}

Keywords: AES, JE, non JE, cytokine, IP- 10.

\section{Introduction}

Acute Encephalitic syndrome is a surveillance definition [1]. In India, the Japanese encephalitis (JE) virus, [1] herpes simplex and enteroviruses [2] have been identified as major causative agents of encephalitis. In approx $70 \%$ cases etiology cannot be ascertained [3]. JE has been the cause of viral encephalitis in eastern Uttar Pradesh in India since 1978 , but in recent years changing trends in the etiology have been reported. Data collected from this region over the years has shown, that despite a falling incidence of JE as a cause of encephalitis, the incidence of encephalitis still remains the same [4]. No confirmed viral aetiological agent could be isolated in these cases and they are commonly grouped as non-JE encephalitis. These patients also show distinctive clinical features which are different from those seen in classical JE infection [5].

Cytokines are integral part of immune response to any infection. The earliest host responses to viral infections are nonspecific and induce cytokines resulting in facilitation of the both arms of immunity [6],[7]. Many cytokines are known to play important roles in the development of host defense against viral infections. While cytokines such as IFN $\alpha$, IFN- $\beta$ and TNF- $\gamma$ have the potential to trigger activation of intracellular antiviral pathways after they bind to specific receptors on the surface of the infected cells, other cytokines like IL-1 ,IL-2, IL-6, IL-12, IL-13 and IL-18 are believed to contribute to the antiviral response indirectly by modulating various aspects of the immune response [8]. It has also been shown that cytokines not only play a central role in modulating the immune responses and inflammatory reactions but some cytokines like IL-1, TNF- $\gamma$ can also have direct cytotoxic effects [9]. Previous studies have attributed the neuronal injury in patients with viral encephalitis to a number of proinflammatory cytokines [10].

Since the etiology in most cases of encephalitis cannot be ascertained, differentiating between various etiologies can be on a clinical basis and the cytokine response of various viruses may also be different. Thus, the main aim of this study was to record differences, if any, in the and the immune response in confirmed JE and non-JE encephalitis cases.

\section{Methodology}

This cohort study was performed from July to October 2011. Consecutive patients with acute encephalitis syndrome (AES) aged 1 to 15 years who had been admitted to a tertiary care teaching hospital were enrolled for the study. Clinically, a case of AES is defined by the WHO, as a person of any age, at any time of year, with the acute onset of fever and a change in their mental status (including symptoms such as confusion, disorientation, coma or the inability to talk) and/or new onset seizures (excluding simple febrile seizures). Based on the CSF examination patients with bacterial meningitis (bacterial culture also) and tuberculous meningitis were excluded. Patients testing positive for malaria (MERISCREEN Malaria Pf/Pv Ab: Meril Diagnostics) and typhoid fever (Typhi Check Standard Diagnostic USA) were also excluded from the analysis. Cerebrospinal fluid (CSF) and serum samples were tested for: JE (anti JE IgM MAC ELISA), Dengue (Standard Diagnostic USA), Mumps and Measles (siemans antimeasles virus ELISA).

Patients testing positive for JE, either in serum or CSF were considered to be confirmed JE. Other cases that indicated a viral aetiology without any detectable aetiological agent, were grouped as non-JE patients. Clinical features and detailed investigation of JE cases were compared with the non-JE cases.

Serum and CSF samples of JE positive and non JE cases were further analysed for cytokine levels- Tumor necrosis factor $-\alpha$, Interferon- $\gamma$, Interleukin-10 and chemokines interferon activated protein-10(IP-10) and RANTES by Duo 


\section{International Journal of Science and Research (IJSR) \\ ISSN (Online): 2319-7064}

Index Copernicus Value (2013): 6.14 | Impact Factor (2014): 5.611

ELISA kit (R\&D Systems) according to the manufacturers' instructions.

\section{Statistical analysis}

Data collected from study was entered into a master chart. Mean and standard deviations were calculated for all continuous variables. Student t-test was used to determine if the difference between the means was statistically significant. A p value $<0.05$ were regarded as significant. To test the efficacy of tumour markers as diagnostic test for discrimination between JE encephalitis and non-JE encephalitis, receiver operating curves (ROC) were plotted. All statistical analysis was done using graphpad Prism 5 statistical software and STATA-12.

\section{Results}

A total of 87 AES patients were included in the study. Seventeen patients were excluded from the study for the following reasons: 4 had pyogenic meningitis (CSF culture showed the following causative agents: Streptococcus pneumoniae); 5 patients were positive for malarial as tested by the rapid diagnostic test for malaria parasite and two were IgM typhoid. Measles IgM was positive in 5 cases, HSV IgM in 1 case; Mumps IgM and Dengue IgM was not positive in any. Twelve patients were classified as confirmed JE cases on the basis of positive IgM ELISA in serum or CSF. Fifty eight with probable viral encephalitis, where no virus was detected, were grouped under non-JE cases.

Cytokines were tested in 45 patients, 12 were positive for JE IgM and rest 33 cases were from the Non JE category. Serum and CSF levels of the TNF- $\alpha$ and RANTES in both groups were high but no significant difference in the rise between the groups was found. When comparing the Serum and CSF level of IFN- $\gamma$, IL-10 and IP-10 were significantly higher in Non JE patients than in JE patients (Fig 1a-1e \& 2a-2e). ROC curves were drawn to test the diagnostic efficacy of TNF- $\alpha$, Interferon-Y, RANTES, IL-10 and IP-10 to establish if any of these markers could help differentiating between JE and non-JE encephalitis. Only IP-10 with AUC of 0.8043 was a good choice for such differentiation. A cut-off value of IP-10 more than 1223.24 was helpful in differentiating nonJE from JE with a sensitivity of $72.73 \%$ and specificity of $66.63 \%$ (AUC $=0.8043$, CI 0.67468-0.93391) (Fig-III). Interferon gamma and IL-10 levels were not found to be diagnostic. (figure 3 a-e).

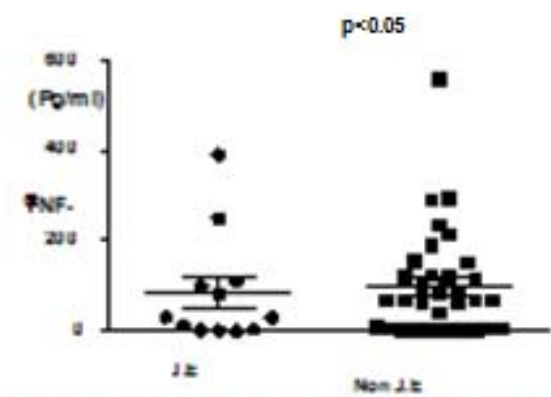

Figure (1a)-senum TNF- $\alpha$ in JE and non JE patients

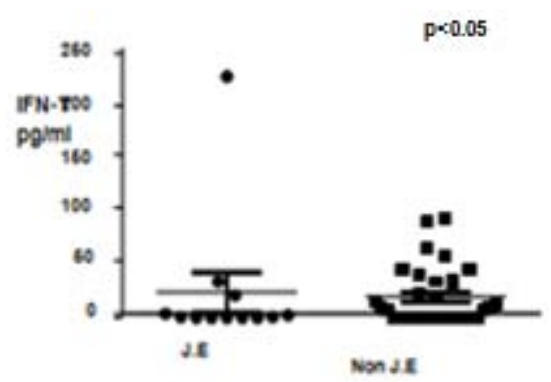

Figure(1b)-serum IFN- $\gamma$ in JE and non JE patients

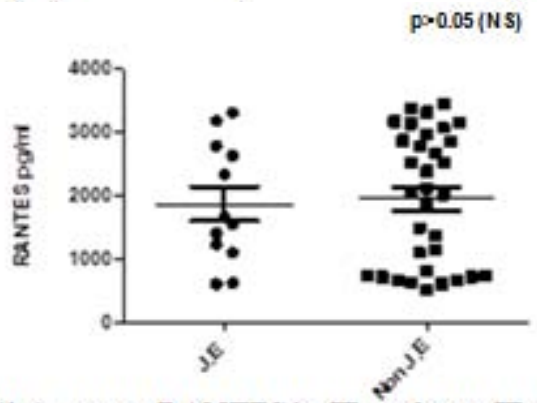

Figure (1c)- serum RANTES in JE and non JE patients

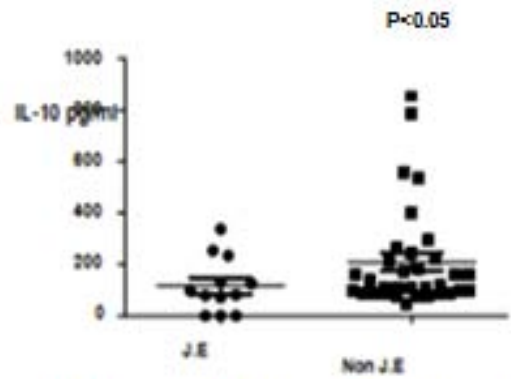

Figure (1d)-serum IL-10 in JE and non JE patients P.0.05

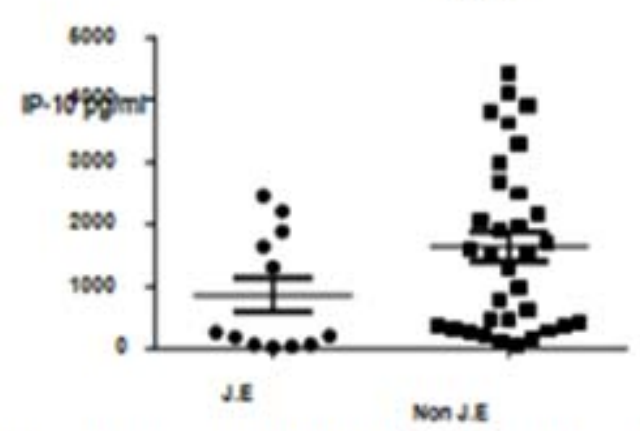

Figure (1e)-serum IP-10 in JE and non JE patients

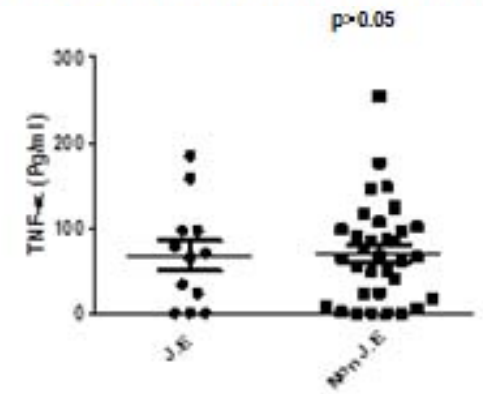

Figure (2a)-CSF TNF- $\alpha$ in JE and non JE patients 


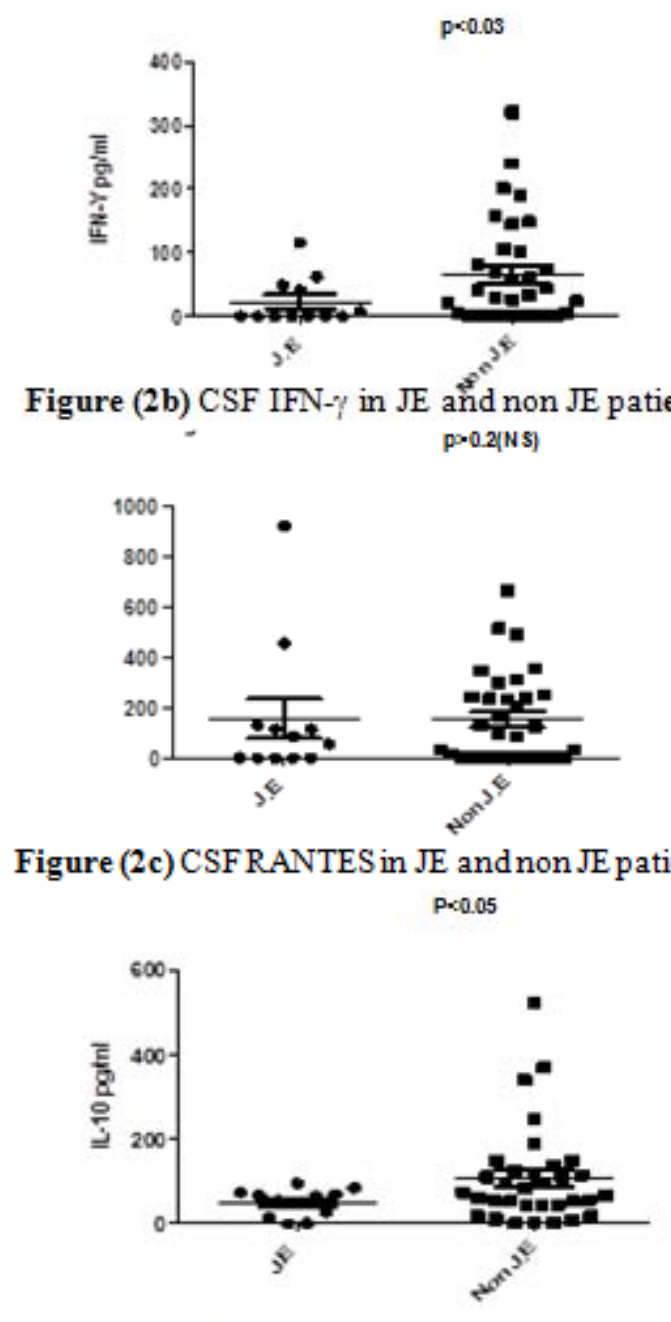

Figure (2d) CSF IL-10 in JE and non JE patients

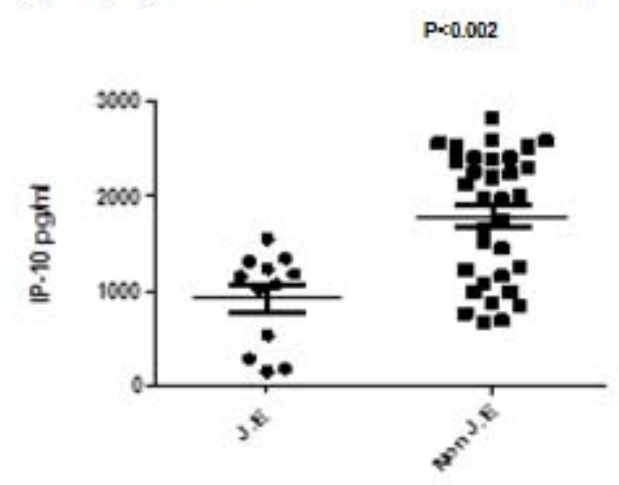

Figure (2e) CSF IP-10 in JE and non JE patients

\section{Discussion}

This study highlights a difference in immunological response of the JE and non JE cases. It appears that non JE infection initiates an inflammatory response with marked release of IP-10. Other inflammatory markers like IFN- $\gamma$, IL-10 and IP10 are also significantly raised in Non JE patients as compared to JE. In our study group interferon gamma inducible protein (CXCL-10), a chemokine was significantly increased in the non JE group. It also turned out to be a fairly sensitive test in differentiating JE from non JE.

Cytokines play a significant role in the development of an acute or chronic inflammatory response, and many chemokines exhibit redundant and pleiotropic effects that work together and contribute to the inflammatory response [11]. IP-10 is a CXC chemokine secreted by several cell types, including macrophages, microglia and astrocytes in response to stimuli, such as interferon (IFN)- $\alpha$, IFN- $\beta$, IFN- $\gamma$ or viruses. [12]-[15]. It is a potent chemoattractant for NK cells and particularly $\mathrm{T}$ cells during viral infection [16]-[18]. It is also a fascinating chemokine because of its controversial roles in viral infection. It has been implicated to aggravate diseases in mice infected with mouse hepatitis virus, herpes simplex virus or lymphocytic choriomeningitis virus, and in humans infected with human immunodeficiency virus, hepatitis $\mathrm{C}$ virus or severe acute respiratory syndrome coronavirus [19]-[24]. However, endogenous IP-10 has been shown to protect mice infected with coxsackievirus B3, dengue virus, herpes simplex virus or mouse hepatitis virus by promoting viral clearance in tissues [16],[18],[25],[26] . IP-10 can suppress viral infection by recruiting mainly leukocytes [16],[17],[26],[27] or directly by inhibiting viral replication [25],[28]. Moreover, leukocyte recruitment mediated by IP-10 varies with the infecting virus and infected organ [16],[17],[26],[27]. Several independent studies showed that EV71- infected patients with BE (brain stem encephalitis) and PE (pulmonary edema) exhibit various elevated chemokines and cytokines, including interferon (IFN)- $\gamma$ (a Th1 cytokine), IL-6 (a pleiotropic cytokine), IL-1 $\beta$ (a pro-inflammatory cytokine, IL-10 (an immunoregulatory cytokine), IL-13 (a Th2 cytokine), and the chemokines IL-8) and IP-10 [29],[30] among others. Thus, IP10 is being increasingly used in the pathogenesis, assessing the severity and prognosis for many viral illnesses and non viral illnesses.

JE infection is on the decline in this region [6] and with the changing landscape it can be concluded, that IP-10 may be a useful clinical marker to identify non JE from JE. Its usefulness could be further studied for determining the pathogenesis of non JE AES, the etiology of which remains undetermined and may be a explored as a potential therapeutic target for the future. 


\section{International Journal of Science and Research (IJSR) \\ ISSN (Online): 2319-7064}

Index Copernicus Value (2013): 6.14 | Impact Factor (2014): 5.611

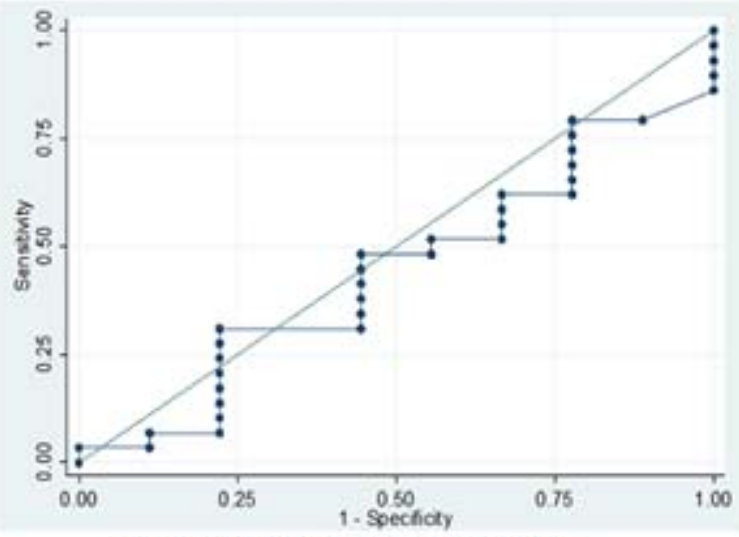

Area under ROC curve $=0.4406$

Figure (3a): ROC for TNF- $\alpha$ in diagnosing Non-JE encephalitis in csf

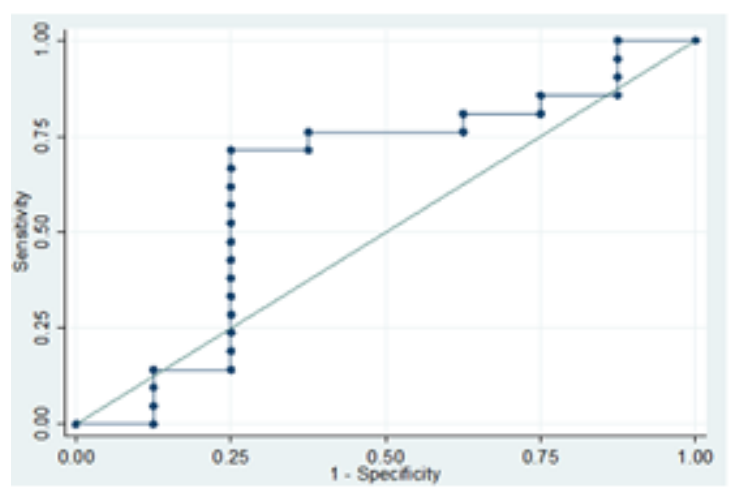

Area under ROC curve $=0.6310$

Figure (3c): ROC for RANTES in diagnosing NonJE encephalitis

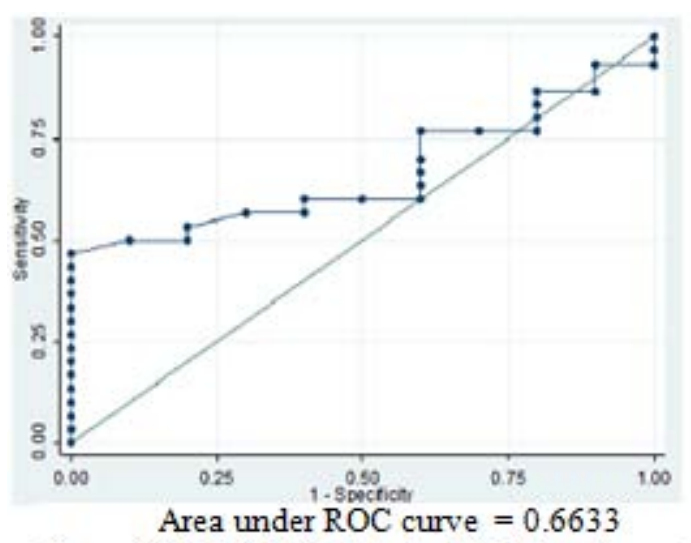

Figure (3d) ROC for Interleukin 10 in diagnosing Non-JE encephalitis in csf

\section{References}

[1] Directorate of National Vector Borne Diseases Control Programme. Guidelines for surveillance of acute encephalitis syndrome (with special reference to Japanese encephalitis) [cited 2012 Sept 27]. http://www.nvbdcp.gov.in/Doc/AES\%20guidelines. pdf for acute viral encephalitis which is caused by a wide range of viruses.

[2] Saxena SK, Mishra N, Saxena R, Singh M, Mathur A. Trend of Japanese encephalitis in north India:

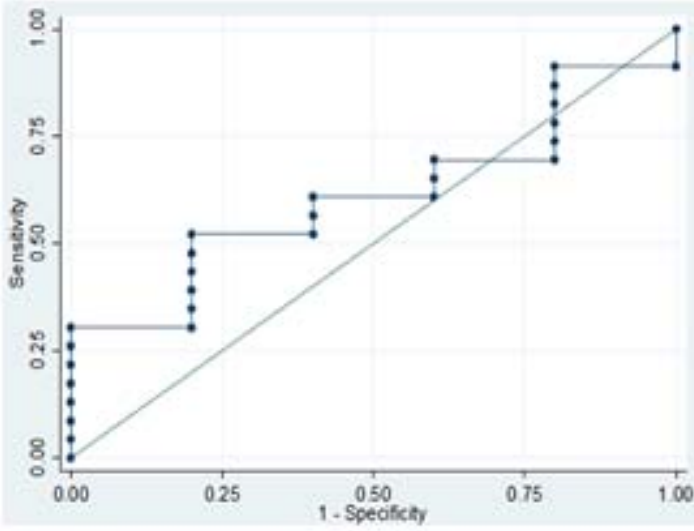

Area under ROC curve $=0.6087$

Figure (3b): ROC for Interferon-Y in diagnosing Non-JE encephalitis in csf

\begin{tabular}{|l|l|}
\hline \multicolumn{1}{|l|}{ AUROCC } & Interpretation \\
\hline 1.0 & Perfect test \\
\hline 0.9 to 0.99 & Excellent test \\
\hline 0.8 to 0.89 & Good test \\
\hline 0.7 to 0.79 & Fair test \\
\hline 0.51 to 0.69 & Poor test \\
\hline \\
$0.5-$ Negative predictor \\
$<0.5-$ Worthless test \\
0.5 to $1.0-$ Positive predictor \\
* Area under ROC curve
\end{tabular}

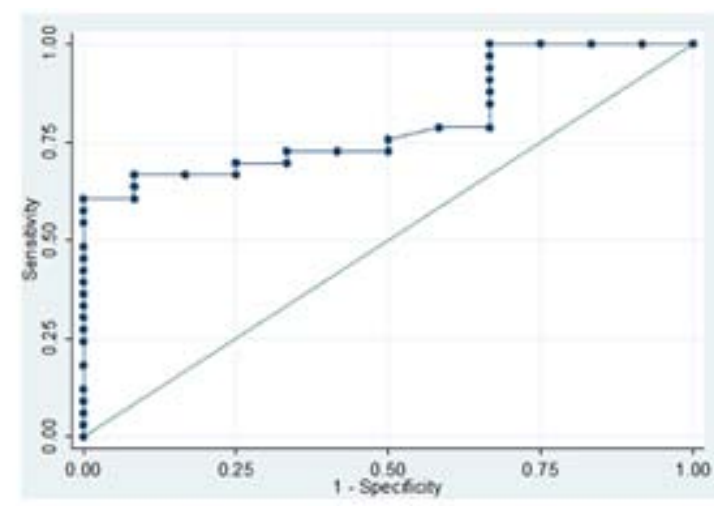

Area under ROC curve $=0.8043$

Figure ( $3 \mathrm{e}$ ) ROC for IP 10 in diagnosing Non-JE encephalitis in csf

evidence from thirty eight acute encephalitis patients and appraisal of niceties. J Infect Dev Ctries. 2009;30:517-30.

[3] Kennedy PG. Viral encephalitis: causes, differential diagnosis and management. J Neurol NeurosurgPsychiatry. 2004;75:10-5.

[4] Bhatt GC, Bondre VP, Sapkal GN, Sharma T, Kumar S, Gore MM, Kushwaha KP, Rathi AK. Changing clinico-laboratory profile of encephalitis patients in the eastern Uttar Pradesh region of India. Trop Doct. 2012 Apr;42(2):106-8. 


\section{International Journal of Science and Research (IJSR) \\ ISSN (Online): 2319-7064}

Index Copernicus Value (2013): 6.14 | Impact Factor (2014): 5.611

[5] Beig FK, Malik A, Rizvi M, Acharya D, Khare S. Etiology and clinico-epidemiological profile of acute viral encephalitis in children of western Uttar Pradesh, India. Int J Infect Dis. 2010 Feb;14(2):e141-6.

[6] C.A. Biron, G.C. Sen. Interferons and other cytokines, in: D.M. Knipe, P.M. Howley (Eds.), Fields Virology, 4th edn, Lippincott Williams and Wilkins, Philadelphia, 2001, pp. 321-352.

[7] S. Goodbourn, L. Didcock, R.E. Randall. Interferons: cell signaling, immune modulation, antiviral response and virus counter measures. J. Gen. Virol. 2000;81:2341-2364.

[8] A. Thomson. The Cytokine Handbook, 3rd edn, Academic Press, San Diego, 1998.

[9] V.J. Quagliarello, B. Wispelwey, W.J. Long, W.M. Scheid. Recombinant human interleukin-1 induces meningitis and blood-brain barrier injury in the rat. J. Clin. Invest. 1991;87:1360-1366.

[10] P.M.Winter, N.M. Dung, H.T. Loan, R. Kneen, B. Wills, L.T. Thu. Proinflammatory cytokines and chemokines in humans with Japanese encephalitis. J. Infect. Dis. 2004;190:1618-1626.

[11] Stein JV, Nombela-Arrieta C. Chemokine control of lymphocyte trafficking: a general overview. Immunology. 2005;116(1):1-12.

[12] Lane T E, Asensio VC, Yu N, Paoletti AD, Campbell IL, Buchmeier MJ. Dynamic regulation of alpha- and betachemokine expression in the central nervous system during mouse hepatitis virus-induced demyelinating disease. J Immunol. 1998 Jan 15;160(2):970-8.

[13] Marques CP, Hu S, Sheng W, Lokensgard JR. Microglial cells initiate vigorous yet non-protective immune responses during HSV-1 brain infection. Virus Res. 2006 Oct;121(1):1-10.

[14] Vanguri P, Farber JM. Identification of CRG-2. An interferon-inducible mRNA predicted to encode a murine monokine. J Biol Chem. 1990 Sep 5;265(25):15049-57.

[15] Vanguri P, Farber JM. IFN and virus-inducible expression of an immediate early gene, crg-2/IP-10, and a delayed gene, I-A alpha in astrocytes and microglia. J Immunol 1994 Feb 1;152(3):1411-8.

[16] Thapa M, Welner RS, Pelayo R, Carr DJ. CXCL9 and CXCL10 expression are critical for control of genital herpes simplex virus type 2 infection through mobilization of HSV-specific CTL and NK cells to the nervous system. J Immunol 2008 Jan 15;180(2):1098-106.

[17] Trifilo MJ, Montalto-Morrison C, Stiles LN, Hurst KR, Hardison JL, Manning JE, Masters PS, Lane TE. CXC chemokine ligand 10 controls viral infection in the central nervous system: evidence for a role in innate immune response through recruitment and activation of natural killer cells. J Virol. 2004 Jan;78(2):585-94.

[18] Yuan Ji, Liu Zhen, Lim T, Zhang H, He J, Walker E, Shier C, Wang Y, Su Y, et al. CXCL10 inhibits viral replication through recruitment of natural killer cells in coxsackievirus B3- induced myocarditis. Circ Res. 2009; 104:628-638.
[19] Carr DJ, Chodosh J, Ash J, Lane TE. Effect of antiCXCL10 monoclonal antibody on herpes simplex virus type 1 keratitis and retinal infection. J Virol 2003 Sep;77(18):10037-46.

[20] Christensen JE, Simonsen S, Fenger C, Sørensen MR, Moos T, Christensen JP, Finsen B, Thomsen AR. Fulminant lymphocytic choriomeningitis virus-induced inflammation of the CNS involves a cytokine-chemokine-cytokine-chemokine cascade. J Immunol. 2009 jan 15;182(2):1079-87.

[21] Dufour JH, Dziejman M, Liu MT, Leung JH, Lane TE, Luster AD. IFN-gamma-inducible protein 10 (IP-10; CXCL10)-deficient mice reveal a role for IP-10 in effector $\mathrm{T}$ cell generation and trafficking. J Immunol. 2002 Apr 1;168(7):3195-204.

[22] Harvey CE, Post JJ, Palladinetti P, Freeman AJ, Ffrench RA, Kumar RK, Marinos G, loyd AR. Expression of the chemokine IP-10 (CXCL10) by hepatocytes in chronic hepatitis $\mathrm{C}$ virus infection correlates with histological severity and lobular inflammation. J Leukoc Biol. 2003 Sep;74(3):360-9.

[23] Kolb SA, Sporer B, Lahrtz F, Koedel U, Pfister HW, Fontana A. Identification of a $\mathrm{T}$ cell chemotactic factor in the cerebrospinal fluid of HIV-1-infected individuals as interferongamma inducible protein 10. J Neuroimmunol. 1999 jan $1 ; 93(1-2): 172-81$.

[24] Tang NL, Chan PK, Wong CK, To KF, Wu AK, Sung YM, Hui DS, Sung JJ, Lam CW. Early enhanced expression of interferon-inducible protein-10 (CXCL-10) and other chemokines predicts adverse outcome in severe acute respiratory syndrome. Clin Chem. 2005 Dec;51(12):2333-40.

[25] Chen JP, Lu HL, Lai SL, Campanella GS, Sung JM, Lu MY, Wu-Hsieh BA, Lin YL, Lane TE, Luster $\mathrm{AD}$, Liao F. Dengue virus induces expression of CXC chemokine ligand 10/IFN-gamma-inducible protein 10, which competitively inhibits viral binding to cell surface heparan sulfate. J Immunol. 2006;177(5):3185-3192.

[26] Walsh KB, Edwards RA, Romero KM, Kotlajich MV, Stohlman SA, Lane TE. Expression of CXC chemokine ligand 10 from the mouse hepatitis virus genome results in protection from viral-induced neurological and liver disease. J Immunol. $2007 \mathrm{Jul}$ 15;179(2):1155-65.

[27] Lindell DM, Lane TE, Lukacs NW. CXCL10/CXCR3 - mediated responses promote immunity to respiratory syncytial virus infection by augmenting dendritic cell and $\mathrm{CD} 8+\mathrm{T}$ cell efficacy. Eur J Immunol. 2008 Aug;38(8):2168-79.

[28] Lokensgard JR, Hu S, Sheng W, vanOijen M, Cox D, Cheeran MC, Peterson PK. Robust expression of TNF-a, IL-1b, RANTES, and IP-10 by human microglial cells during non-productive infection with herpes simplex virus. J Neurovirol. 2001 Jun;7(3):208-19.

[29] Wang SM, Lei HY, Huang KJ, Wu JM, Wang JR, et al. Pathogenesis of enterovirus 71 brainstem encephalitis in pediatric patients: roles of cytokines and cellular immune activation in patients with pulmonary edema. J Infect Dis 2003;188: 564-570. 


\section{International Journal of Science and Research (IJSR) \\ ISSN (Online): 2319-7064}

Index Copernicus Value (2013): 6.14 | Impact Factor (2014): 5.611

[30] Chang LY, Hsiung CA, Lu CY, Lin TY, Huang FY, et al. Status of cellular rather than humoral immunity is correlated with clinical outcome of enterovirus 71. Pediatr Res. 2006; 60: 466-471.

\section{Author Profile}

Mahima Mittal, Associate Professor, Department of Pediatrics, BRD Medical College, Gorakhpur, UP (India)273013.

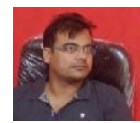

Mohammed Junaid Ansari, Lecturer, Department of Pediatrics, BRD Medical College, Gorakhpur, UP (India)-273013.

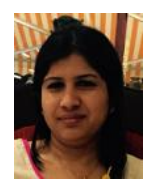

Shahla Abrar, Senior Resident, Department of Pediatrics, BRD Medical College, Gorakhpur, UP (India)- 273013

Ashok Kumar Pandey, National Institute of Virology, Gorkhpur Unit, Gorakhpur, UP (India)- 273013 